\title{
Identification of a Protein Linked to Nascent Poliovirus RNA and to the Polyuridylic Acid of Negative-Strand RNA
}

\author{
RALF F. PETTERSSON, $†$ VICTOR AMBROS, AND DAVID BALTIMORE* \\ Department of Biology and Center for Cancer Research, Massachusetts Institute of Technology, Cambridge,
} Massachusetts 02139

Received for publication 26 January 1978

\begin{abstract}
A protein similar to that previously demonstrated on poliovirus RNA and replicative intermediate RNA (VPg) was found on all sizes of nascent viral RNA molecules and on the polyuridylic acid isolated from negative-strand RNA. ${ }^{32} \mathrm{P}$ labeled nascent chains were released from their template RNA and fractionated by exclusion chromatography on agarose. Fingerprint analysis using two-dimensional polyacrylamide gels of RNase T1 oligonucleotides derived from nascent chains of different lengths showed that a size fractionation of nascent chains was achieved. VPg was recovered from nascent chains varying in length from 7,500 nucleotides (full-sized RNA) to about 500 nucleotides. No other type of $5^{\prime}$ terminus could be demonstrated on nascent RNA, and the yield of VPg was consistent with one molecule of the protein on each nascent chain. These results are consistent with the concept that the protein is added to the $5^{\prime}$ end of the growing RNA chains at a very early stage, possibly as a primer of RNA synthesis. Analysis of the polyuridylic acid tract isolated from the replicative intermediate and double-stranded RNAs indicated that a protein of the same size as that found on the nascent chains and virion RNA is also linked to the negative-strand RNAs. It is likely that a similar mechanism is responsible for initiation of synthesis of both plus- and minus-strand RNAs.
\end{abstract}

Unlike any other known viral RNA, the virion RNAs of several picornaviruses, including poliovirus, have a protein (VPg) covalently linked to their $5^{\prime}$ terminus $(7,10,12,15)$. In the case of poliovirus, the protein is linked to an oligonucleotide with the sequence: $\mathrm{VPg}-\mathrm{U}-\mathrm{U}-\mathrm{A}-\mathrm{A}-\mathrm{A}-\mathrm{A}$ C-A-Gp ... $(7,12)$. The mRNA isolated from the polyribosomes of infected cells, however, lacks the protein and terminates at its $5^{\prime}$ end in $\mathrm{pU}$ U-A-A-A-A-C-A-Gp (13). Thus, the only apparent difference between these RNAs, which have the same polarity and specific infectivity (7), is the presence or absence of the protein which appears to be virus specified (12) and has a molecular weight of about 12,000 (Ambros and Baltimore, submitted for publication). The protein is also found in preparations of replicative intermediate (RI) RNA (7), the structure in which new viral RNA is synthesized (2). This finding led to the suggestion that the protein, possibly linked to one or several nucleotides, might serve as a primer for initiating poliovirus RNA synthesis. Subsequently, the protein would be cleaved from the strands destined to become

$\dagger$ Present address: Department of Virology, University of Helsinki, Helsinki, Finland.
mRNA; RNA retaining the protein would be encapsidated into mature virions $(7,13)$.

In this paper we report the isolation and fractionation of nascent chains from RI RNA and show that the protein is found on newly synthesized chains as short as about 500 nucleotides. In addition, the protein was recovered in covalent linkage to the $5^{\prime}$ end of the polyuridylic acid [poly(U)] tract isolated from the negative strands of both RI RNA and double-stranded RNA, a finding also recently reported by Nomoto et al. (12). These results are consistent with the idea that the protein serves as a primer for synthesis of both the plus and the minus strands of poliovirus RNA.

\section{MATERIALS AND METHODS}

Preparation of poliovirus RNA. Poliovirus-specific RNA labeled with carrier-free ${ }^{32} \mathrm{P}$ (New England Nuclear Corp.) was prepared by infecting actinomycin D-treated HeLa cells with poliovirus type $1(3,8)$. Preparations of ${ }^{32} \mathrm{P}$-labeled virion RNA, RI RNA, and double-stranded RNA were as described previously (16).

Fractionation of nascent chains from RI RNA. RI RNA, which had been recovered from the excluded volume of a Sepharose $2 \mathrm{~B}$ column, was precipitated with 2.5 volumes of ethanol at $-20^{\circ} \mathrm{C}$ in the 
presence of $0.3 \mathrm{M}$ sodium acetate. The precipitate was collected by centrifugation and dissolved in distilled water treated with $0.01 \%$ diethylpyrocarbonate, and sodium dodecyl sulfate was added to $0.5 \%$. In some experiments unlabeled virion 35S RNA (final concentration, 50 to $100 \mu \mathrm{g} / \mathrm{ml}$ ) was included. The RNA was then heated at $75^{\circ} \mathrm{C}$ for $5 \mathrm{~min}(1)$ and quickly cooled on ice, and glycerol was added to a final concentration of $8 \%$. The sample, usually 0.5 to $1.0 \mathrm{ml}$, was layered on a Sepharose $2 B$ column $(1.6$ by $54 \mathrm{~cm})(1)$, and the RNA was eluted with a solution containing $0.1 \mathrm{M}$ $\mathrm{NaCl}, 0.05 \mathrm{M}$ Tris-hydrochloride (pH 7.5), $0.001 \mathrm{M}$ EDTA, and $0.5 \%$ sodium dodecyl sulfate. Fractions (1 $\mathrm{ml}$ ) were collected and assayed for Cerenkov radiation. The RNA in the fractions to be analyzed was precipitated with ethanol and stored at $-20^{\circ} \mathrm{C}$. Size calibration of the column was done by chromatographing ${ }^{32} \mathrm{P}$ labeled Uukuniemi virus RNA segments under identical conditions. The three RNA segments have apparent molecular weights of $2.4 \times 10^{6}$ (L RNA), $1.1 \times$ $10^{6}$ (M RNA), and $0.5 \times 10^{6}$ (S RNA) (14). A linear relationship was observed between the logarithm of the molecular weights and the corresponding elution position.

Fingerprint analysis of RNA. Labeled virion RNA and different size classes of molecules released from the RI RNA were digested with RNase T1 and analyzed on two-dimensional polyacrylamide gels, as described previously $(6,14)$. The radioactive spots were visualized by autoradiography, using Kodak XR5 film. The unique oligonucleotides derived from virion RNA were numbered according to Lee and Wimmer (11). Quantitation of individual spots was done by cutting out gel slices and counting Cerenkov radiation.

Isolation of poly(U) from RI and doublestranded RNAs. Purified labeled RI RNA or doublestranded RNA, which were excluded from Sepharose $2 \mathrm{~B}$, were precipitated with ethanol and dried in vacuo. The RNA was suspended in $100 \mu \mathrm{l}$ of distilled water containing $5 \mu \mathrm{g}$ of unlabeled poly(U) (Miles Laboratories, Inc.). The RNA was then denatured for $1.5 \mathrm{~min}$ at room temperature by the addition of $100 \mu \mathrm{l}$ of $0.2 \mathrm{~N}$ $\mathrm{NaOH}$ (17). The solution was neutralized by the addition of $3.5 \mathrm{ml}$ of a buffer containing $0.25 \mathrm{M}$ Tris, $\mathrm{pH}$ 7.5 , and $30 \mathrm{mM}$ sodium acetate. RNase T1 was added to a final concentration of $40 \mathrm{U} / \mathrm{ml}$, and the sample was incubated for $60 \mathrm{~min}$ at $37^{\circ} \mathrm{C}$. After digestion, the solution was adjusted to $0.3 \mathrm{M} \mathrm{NaCl}$ and $0.5 \%$ sodium dodecyl sulfate. Poly(U)-containing sequences were then isolated by chromatography on polyadenylic acid [poly(A)]-agarose [AGPOLY(A), type 6; P-L Biochemicals]. The RNase digest was passed through the column twice, and the column was washed extensively with high-salt buffer $(0.3 \mathrm{NaCl}-10 \mathrm{mM}$ Tris, $\mathrm{pH}$ $7.5-0.5 \%$ sodium dodecyl sulfate). The column was then heated to $65^{\circ} \mathrm{C}$ and washed with high-salt buffer preheated to $65^{\circ} \mathrm{C}$. This step usually released some radioactivity relatively rich in Ap. The poly(U)-containing sequences were eluted at $65^{\circ} \mathrm{C}$ with $90 \%$ formamide (deionized by stirring in a mixed-bed resin) containing $25 \mu \mathrm{g}$ of cold poly(U) per $\mathrm{ml}, 10 \mathrm{mM}$ Tris (pH 7.5), and $1 \mathrm{mM}$ EDTA. The eluted material was pooled and precipitated with ethanol. The precipitate was taken up in $20 \mathrm{mM}$ Tris, pH 7.5-2 mM EDTA, denatured by boiling for $2 \mathrm{~min}$, and quickly cooled on ice. Digestion with RNase T1 $(40 \mathrm{U} / \mathrm{ml})$ and chromatography on poly(A)-agarose were repeated as described above, and the final poly $(U)$ preparation was precipitated with ethanol.

Sodium dodecyl sulfate-polyacrylamide gel analysis. The protein covalently linked to poliovirus RNA species was prepared as described elsewhere (Ambros and Baltimore, submitted for publication). Briefly, labeled RNA was digested to mononucleotides with a mixture of RNases T1, T2, and A, followed by phenol extraction. The protein was then precipitated from the phenol phase with 9 volumes of acetone at $-20^{\circ} \mathrm{C}$. Bovine serum albumin $(10 \mu \mathrm{g})$ and cytochrome c (about $5 \mu \mathrm{g}$ ) were included as carriers throughout the procedure. The precipitated protein was collected by centrifugation, dried in vacuo, taken up in sample buffer, boiled for $2 \mathrm{~min}$, and analyzed on a 10 to $20 \%$ gradient slab polyacrylamide gel (9). The gels were fixed, stained, destained, and dried, and an autoradiograph was prepared at $-70^{\circ} \mathrm{C}$ by using Kodak XR-5 films and an intensifying screen. This procedure regularly resulted in a rather broad VPg band, probably due to some acetone-precipitable residue in the phenol. The radioactive bands were cut out from the gel, and the radioactivity was quantitated either by counting Cerenkov radiation or in a toluene-based scintillation fluid (Econofluor; New England Nuclear Corp.). In each experiment, the efficiency of recovery of $\mathrm{VPg}$ was monitored by measuring the recovery of VPg from a known amount of virion RNA. When the unequal labeling of the different mononucleotides is considered, the theoretical yield of radioactivity in protein-pUp is $0.042 \%$ of the total (7). Usually 0.015 to $0.022 \%$ was observed, giving a recovery of $\mathrm{VPg}$ of 25 to $50 \%$.

Base composition analysis. RNA to be analyzed was completely digested with RNases $\mathrm{T} 1, \mathrm{~T} 2$, and A. In some cases the digest was extracted with phenolchloroform-isoamyl alcohol (25:24:1; Ambros and Baltimore, submitted for publication), and the mononucleotides were precipitated from the aqueous phase with 9 volumes of acetone at $-20^{\circ} \mathrm{C}$. The samples were then subjected to ionophoresis at $\mathrm{pH} 3.5$ on Whatman 3MM paper (4). The radioactive spots were visualized by autoradiography, using Kodak XR-5 or No-Screen films. The spots were cut out from the paper and quantitated either by counting Cerenkov radiation or in Econofluor with a Beckman LS-330 scintillator.

\section{RESULTS}

Isolation and fractionation of nascent chains from RI RNA. Poliovirus RI RNA labeled with ${ }^{32} \mathrm{P}$ was extracted from the cytoplasm of infected HeLa cells at $3.5 \mathrm{~h}$ after infection, a time at which the maximum rate of viral RNA synthesis occurs (3). Labeled RNA was precipitated with $2 \mathrm{M} \mathrm{LiCl}$, phenol extracted, and chromatographed on Sepharose 2B (Fig. 1A); as previously determined, the material eluting in the excluded volume consists of more than $95 \%$ pure RI RNA (1). The included material, mainly located in fractions 50 to 60 , consisted of poliovirus 


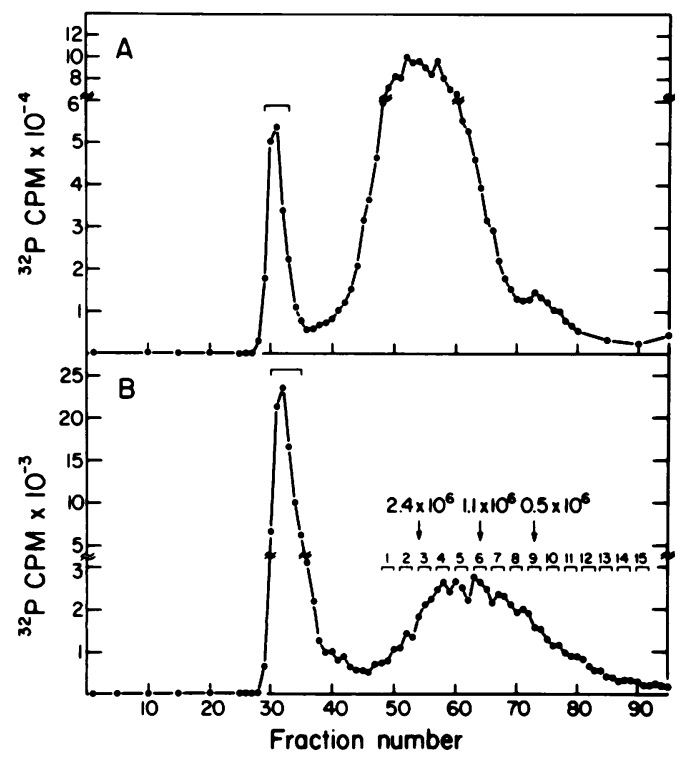

FIG. 1. Fractionation of nascent chains from poliovirus RI RNA. (A) Poliovirus RI RNA labeled with ${ }^{32} \mathrm{P}$ was extracted from $\mathrm{HeLa}$ cells at $3.5 \mathrm{~h}$ after infection and precipitated with $2 \mathrm{M} \mathrm{LiCl}$ at $-20^{\circ} \mathrm{C}$. The precipitate was phenol extracted, and the RNA was precipitated with ethanol. The RI RNA was freed of 35S RNA by chromatography on Sepharose $2 B$. (B) The RNA excluded from the column was pooled and ethanol precipitated. The nascent chains were released from their template by heating at $75^{\circ} \mathrm{C}$ for 5 min (1) and fractionated on Sepharose $2 B$. In both cases 1-ml fractions were collected and assayed for

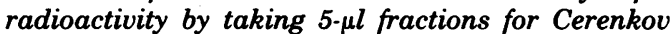
radiation. Fractions containing released nascent chains were pooled as indicated to give $153-\mathrm{ml}$ pools. Uukuniemi virus $L, M$, and $S$ RNA segments labeled with ${ }^{32} P$ (14) were used in separate runs as known molecular weight markers.

35S RNA as shown by sucrose gradient centrifugation analysis (data not shown). To release nascent chains from their minus-strand template, RI RNA was heated at $75^{\circ} \mathrm{C}$ for $5 \mathrm{~min}$, quickly cooled, and immediately rechromatographed on Sepharose 2B (Fig. 1B) (1). This treatment released 40 to $50 \%$ of the radioactivity as RNA that eluted as a much broader peak than 35S RNA; as previously shown, this RNA consists mainly of newly synthesized RNA of plus polarity (1).

To confirm that the released material represented nascent chains and that they were fractionated according to their size, portions of the included broad peak of Fig. 1B were submitted to fingerprint analysis on two-dimensional polyacrylamide gels. If fractionation of nascent chains had occurred, then RNase T1-derived oligonucleotides from the $3^{\prime}$ end of the RNA should have become gradually depleted as the nascent chains became shorter. Fractions from the column were combined into 15 pools (Fig. 1B). Figure 2 shows a set of fingerprints obtained from virion 35S RNA (analyzed in a separate experiment) and from nascent chains from pools 2, 5, and 11. Pool 2, which consists of RNA eluting at the position of full-length virion RNA, contained all the long, unique oligonucleotides of virion RNA and in about the same molar ratio as in virion RNA. With increasing fraction number, certain long oligonucleotides became relatively reduced in intensity. Because oligonucleotide 4 appeared to be the most intense oligonucleotide in the later fractions, we have assumed that it is located closest to the $5^{\prime}$ end of the genome, and the ratio of radioactivity in each spot was therefore calculated relative to the radioactivity in this oligonucleotide. The ratios obtained from virion RNA were taken as $100 \%$, and the ratio in the different pools was then expressed as a percentage of the virion control (Fig. 3). If the order of disappearance of the oligonucleotides is a measure of their relative distance from the $5^{\prime}$ end of the genome, oligonucleotides 4, 11A, and 27B can be located closer to the $5^{\prime}$ end, and oligonucleotides $1,26,28$, and $11 B$ can be located toward the $3^{\prime}$ end. No oligonucleotide disappeared completely, suggesting some random degradation of the RNA and/or poor size fractionation. No spots other than those found in virion RNA could be detected in the fingerprints, indicating that the different pools contained only plus-strand RNA.

When $\mathrm{L}\left(2.4 \times 10^{6}\right.$ daltons $), \mathrm{M}\left(1.1 \times 10^{6}\right.$ daltons), and S (0.5 × $10^{6}$ daltons) RNA segments from Uukuniemi virus (a bunyavirus) (14) were used to calibrate the agarose column, RNA eluting in pools 1 to 3 consisted mainly of fullsized poliovirus RNA $\left(2.4 \times 10^{6}\right.$ daltons $)$, whereas the RNA in pools 14 and 15 had a molecular weight of about 120,000 to 190,000 .

Analysis of the $5^{\prime}$ end of nascent chains. A small protein $(\mathrm{VPg})$ is linked to a pUp residue at the $5^{\prime}$ end of poliovirion RNA. VPg is also found associated with purified RI RNA $(7,12)$. To investigate whether the protein could be recovered from nascent chains of different lengths, pools 1 to 15 (Fig. 1B) were digested with a mixture of RNases T1, T2, and A. This treatment degrades the RNA to $3^{\prime}$-mononucleotides, leaving the protein covalently linked to the $\mathrm{pUp}$ residue (7), and, therefore, the protein can be detected by its content of labeled phosphate. As described elsewhere (Ambros and Baltimore, submitted for publication), the digested RNA was phenol extracted, and the material which was extracted into the phenol phase was precipitated with acetone. The precipitate was 


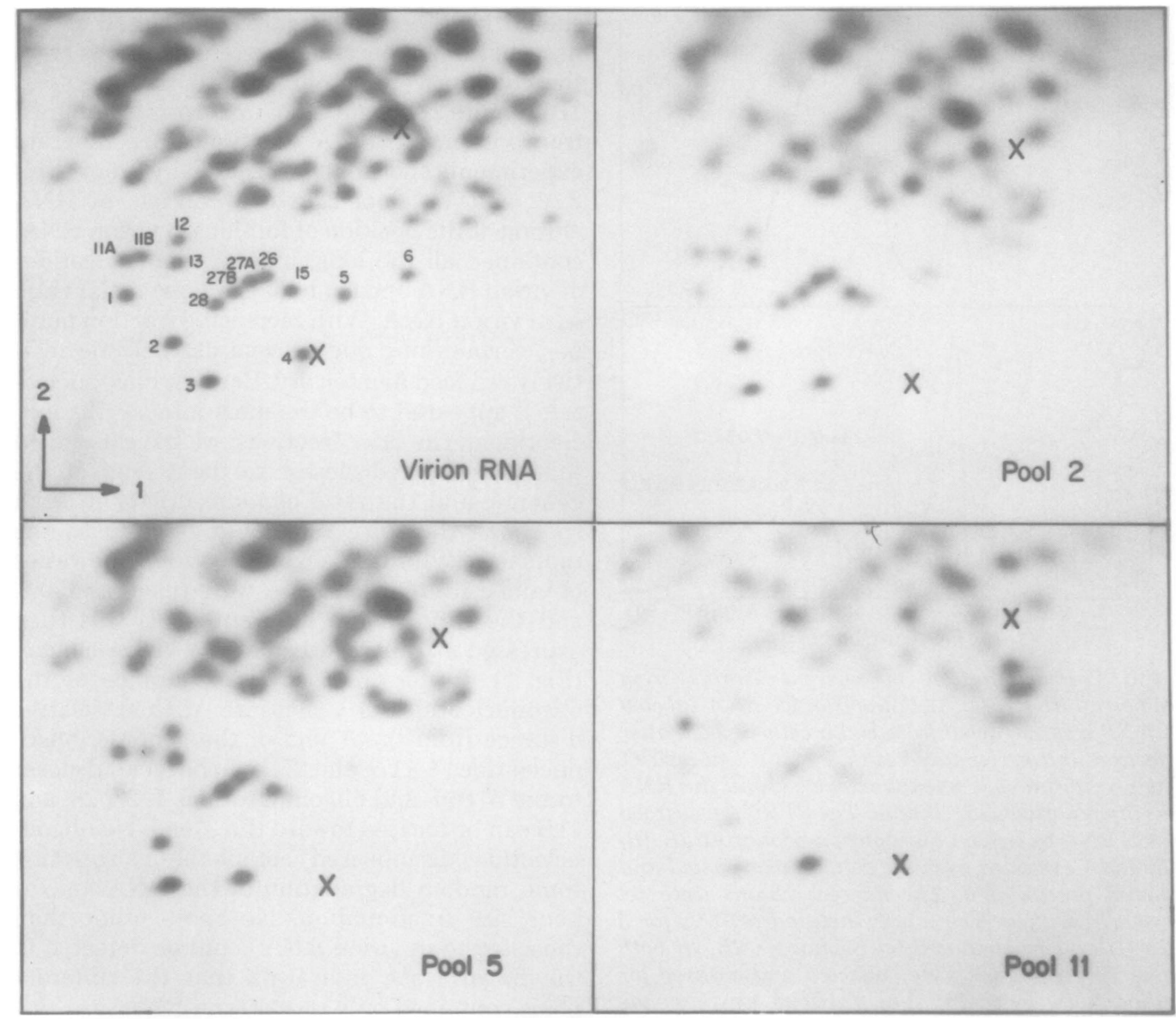

Fig. 2. Two-dimensional gel electrophoresis of ${ }^{32} P$-labeled $T 1$ oligonucleotides from poliovirus $35 S$ RNA and nascent chains. RNase T1 digests of poliovirion RNA and nascent chains from pools 2, 8, and 11 were subjected to two-dimensional gel electrophoresis $(6,14)$. The first dimension was in $10 \%$ acrylamide containing $6 \mathrm{M}$ urea ( $\mathrm{pH}$ 3.5), and the second dimension was in $32 \%$ acrylamide ( $p H$ 8.0). The long oligonucleotides derived from full-sized virion RNA were numbered by the method of Lee and Wimmer (11). The fingerprint analysis of virion RNA was done in a separate experiment. The relative positions of some spots are therefore somewhat different from those in pools 2, 8, and 11. Upper $\times$, bromophenol blue; lower $\times$, xylene cyanol.

then analyzed by polyacrylamide gel electrophoresis. Two samples of ${ }^{32} \mathrm{P}$-labeled virion $35 \mathrm{~S}$ RNA treated similarly were used as controls for the recovery of VPg-pUp (Fig. 4). From each pool, a protein migrating with the same mobility as VPg was recovered. No other species of radioactively labeled protein was detected except in the marker lanes derived from virions; the virion contaminants do not purify with $35 \mathrm{~S}$ RNA. The variable radioactivity that did not enter the gel (Fig. 4) has not been investigated. Calculation of the ratio of the relative molar yield of VPg-pUp to that of the nascent chains in each pool showed that in pools 1 to 7 approximately $1 \mathrm{~mol}$ of $\mathrm{VPg}$ pUp was recovered per mol of RNA chains (Table 1 ). In pools 8 to 15 a decreased recovery of 0.3 to $0.6 \mathrm{~mol}$ of VPg-pUp per mol of RNA chains was observed. Accurate estimation of the ratio in the later pools, however, was difficult (see below).

To study whether any other kind of $5^{\prime}$ end, such as pUp, ppUp, or pppUp, was present on the nascent chains, RNA from each pool was again digested to 3 '-monophosphates by RNases $\mathrm{T} 1, \mathrm{~T} 2$, and $\mathrm{A}$ and subjected to ionophoresis at pH 3.5 on Whatman 3MM paper. Apart from some material $(<3 \%)$ left at the origin and some $\mathrm{P}_{\mathrm{i}}$, no material other than the four standard 3'monophosphates could be detected.

Demonstration of a protein covalently linked to poly(U) from RI RNA and doublestranded RNA. The negative strands of poliovirus RI RNA and double-stranded RNA contain a long stretch of poly(U) (17-19). Although 
the exact location of this homopolymer tract has not been firmly established, location of it at the $5^{\prime}$ end of the minus strand has been suggested (18). To study the structure of the $5^{\prime}$ end of the poly(U) from either source, RI and doublestranded RNAs were extracted from infected cells at 3.5 and $6 \mathrm{~h}$ after infection, respectively, and purified by column chromatography on Sepharose 2B (as in Fig. 1A). The RNAs were

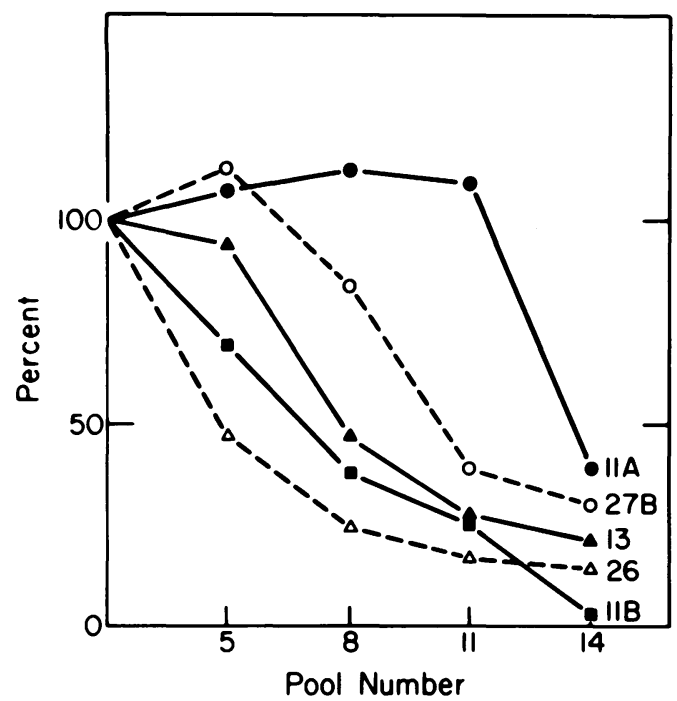

Fig. 3. Recovery of some long T1 oligonucleotides from nascent chains of different lengths. The ratios of radioactivity in oligonucleotides $11 A, 11 B, 13,26$, and $27 B$ to that in oligonucleotide 4 (Fig. 2) were calculated for virion $R N A$. Each ratio was taken as $100 \%$. The same ratios were calculated for the oligonucleotides derived from pools $5,8,11$, and 14 and expressed as percentages of the virion control. denatured and then digested with RNase T1. This treatment should leave a poly(U) tract intact (17) and possibly covalently linked to some residues of $\mathrm{Ap}, \mathrm{Cp}$, and, at the very $3^{\prime}$ end, one residue of $\mathrm{Gp}$. The poly(U) was purified by binding to poly(A)-agarose. After elution with $90 \%$ formamide at $65^{\circ} \mathrm{C}$, the RNA was again denatured, redigested with RNase $T 1$, and repurified on poly(A)-agarose. Figures $5 \mathrm{~A}$ and $\mathrm{B}$ show the purification of poly(U) from RI RNA. The material that eluted from the first poly(A) column rebound to 85 to $90 \%$ in the second cycle. Base composition analysis of this material showed that it consisted of 91 to $93 \% \mathrm{Up}$, about $2.5 \% \mathrm{Cp}, 1 \% \mathrm{Gp}$, and a slightly variable amount of Ap (2.5 to 5\%) (Table 2). No material migrating as pppUp or ppUp was detected, but trace amounts of radioactivity (maximum, $0.2 \%$ ) migrating in the region of $\mathrm{pUp}$ could be seen. To study whether any protein was covalently linked to the poly(U), it was completely digested with RNases T1, T2, and A and phenol extracted, and the acetone-precipitated material from the phenol phase was analyzed by polyacrylamide gel electrophoresis. A ${ }^{32}$ P-labeled protein with the same mobility as VPg could be recovered from the $\operatorname{poly}(\mathrm{U})$ derived from both the RI and double-stranded RNAs (Fig. 6). The recovery of the radioactivity in the protein band was in both cases 1.3 to $1.5 \%$ of the total radioactivity in the poly(U) preparation (Table 2). In one experiment the acetone-precipitated material from the phenol phase was analyzed on a Bio-Gel A-1.5 column. A peak of radioactivity containing $1.3 \%$ of the total radioactivity in poly(U) eluted one fraction behind the cytochrome $c$ marker (Fig. 7), at the same position as VPg (Ambros and Baltimore, submitted for publication). The ma-

TABLE 1. Relative molar yield of nascent RNA chains and VPg from poliovirus RI RNA

\begin{tabular}{|c|c|c|c|c|c|c|}
\hline Pool no. & $\underset{\left(\times 10^{-3}\right)}{\text { cpm in RNA }}$ & Avg chain length & $\begin{array}{l}\text { Relative molar } \\
\text { yield of chains }\end{array}$ & cpm in VPg & $\begin{array}{l}\text { Relative molar } \\
\text { yield of } \mathrm{VPg}^{a}\end{array}$ & $\begin{array}{l}\text { Ratio of VPg to } \\
\text { chains }^{b}\end{array}$ \\
\hline 1 & 405 & 7,500 & & 48 & & \\
\hline 2 & 628 & 7,500 & $1.0^{c}$ & 60 & $1.0^{c}$ & 1.0 \\
\hline 3 & 1,059 & 7,500 & & 88 & & \\
\hline 4 & 1,297 & 5,100 & 2.7 & 136 & 2.1 & 0.8 \\
\hline 5 & 1,299 & 4,050 & 3.5 & 156 & 2.4 & 0.7 \\
\hline 6 & 1,319 & 3,300 & 4.4 & 201 & 3.1 & 0.7 \\
\hline 7 & 1,287 & 2,600 & 5.3 & 291 & 4.5 & 0.8 \\
\hline 8 & 1,068 & 2,050 & 5.6 & 216 & 3.3 & 0.6 \\
\hline 9 & 829 & 1,600 & 5.6 & 229 & 3.5 & 0.6 \\
\hline 10 & 655 & 1,300 & 5.4 & 116 & 1.2 & 0.3 \\
\hline 12 & 278 & 800 & 3.7 & 110 & 1.7 & 0.5 \\
\hline 13 & 178 & 650 & 3.0 & 91 & 1.4 & 0.5 \\
\hline 15 & 64 & 400 & 1.7 & 31 & 0.5 & 0.3 \\
\hline
\end{tabular}

\footnotetext{
${ }^{a}$ Calculated as counts per minute per chain length and normalized to pools 1 to 3 , which contained full-sized virion RNA. VPg was assumed to be linked to pUp.

${ }^{b}$ Ratio of the relative molar yield of VPg to the relative molar yield of nascent chains.

${ }^{c}$ Pools 1, 2, and 3 contained full-sized polioviron RNA, and the mean yields of chains and VPg in these pools were therefore taken as one.
} 


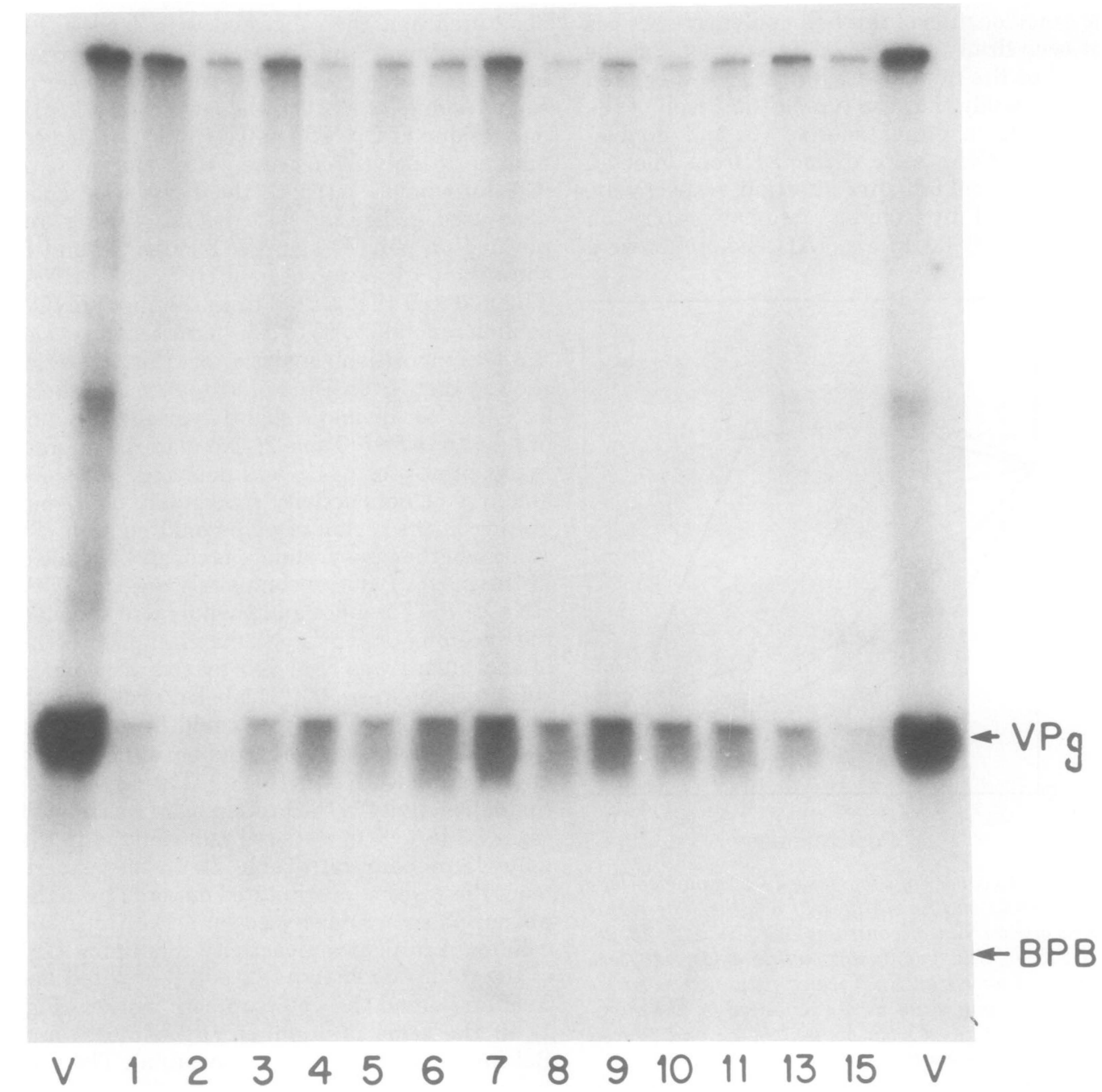

FIG. 4. Sodium dodecyl sulfate-polyacrylamide gel electrophoresis of VPg from nascent chains. RNA from pools 1 to 15 (Fig. 2) was digested with RNases T1, T2, and A and phenol extracted. The protein from the phenol phase was precipitated with acetone and analyzed by electrophoresis through a 10 to $20 \%$ gradient slab gel in sodium dodecyl sulfate (9). Two samples of virion RNA were used as controls (left and right lanes, marked V). The gel was dried, and an autoradiogram was prepared. BPB, Bromophenol blue marker.

terial eluting just ahead of bromophenol blue contained monophosphate (mostly Up) contaminating the phenol phase. The identity of the minor peak eluting ahead of cytochrome $c$ was not established.

VPg isolated from virion RNA is linked to an RNase T1 oligonucleotide of known sequence. This protein-linked oligonucleotide migrates slowly as a discrete band toward the anode upon ionophoresis on cellulose acetate paper at $\mathrm{pH}$ 3.5 (7). To determine whether VPg linked to the $5^{\prime}$ end of the T1 oligonucleotide derived from plus-strand RNA could have contaminated the poly(U) preparations, purified poly(U) was an- alyzed by ionophoresis on cellulose acetate. No trace of the protein-linked oligonucleotide characteristic of virion RNA was detected. Instead, VPg was recovered from a broad band of very fast mobility. Digestion of this band with RNase $\mathrm{U} 2$ released some A residues, leaving almost all radioactivity undigested. Further digestion with RNases T1, T2, and A of the RNase U2-resistant material gave Up (about $95 \%$ ) and some $\mathrm{Cp}, \mathrm{Gp}$, and VPg. The results indicated that $\mathrm{VPg}$, poly(U), and the $C$ and $G$ residues are not interrupted in the sequence by $A$ residues. This was confirmed by digestion of the fast-migrating band from cellulose acetate with pancreatic 


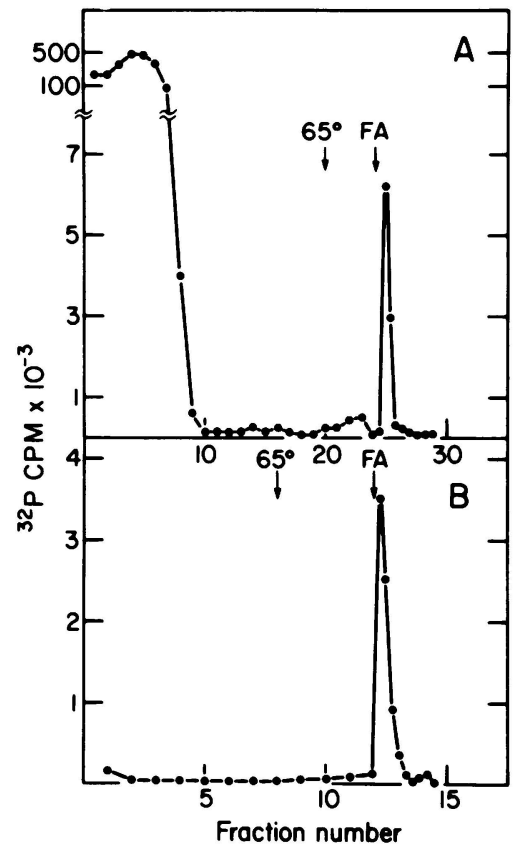

Fig. 5. Poly(A)-agarose chromatography of poly(U) sequences from negative strands of poliovirus RI RNA. (A) Purified ${ }^{32}$ P-labeled RI RNA was denatured with alkali and, after neutralization, digested with RNase T1. The digest was chromatographed on poly $(A)$-agarose in high-salt buffer. The column was washed extensively, then transferred to $65^{\circ} \mathrm{C}$, and washed further with prewarmed high-salt buffer. Poly $(U)$ sequences were eluted with $90 \%$ formamide (FA) in low-salt buffer at $65^{\circ} \mathrm{C}$. (B) The eluted material was again denatured, redigested with RNase T1, and chromatographed a second time through the column. In both cycles 1-ml fractions were collected and assayed for Cerenkov radiation.

TABLE 2. Mononucleotide analysis of poly(A)agarose-bound and RNase T1-resistant sequences from poliovirus $R I$ and double-stranded RNAs

\begin{tabular}{lcccccc}
\hline & \multicolumn{6}{c}{ Base composition (\%) } \\
\cline { 2 - 7 } RNA & Cp & Ap & Gp & Up & pUp & $\begin{array}{l}\text { VPg } \\
\text { pUp }\end{array}$ \\
\hline RI & & & & & & \\
$\quad$ Expt 1 & 2.4 & 2.4 & 1.0 & 92.7 & & 1.5 \\
Expt 2 & 2.5 & 5.0 & 0.9 & 90.2 & 0.2 & 1.3 \\
Double- & 2.3 & 4.8 & 1.1 & 90.5 & & 1.3 \\
$\quad$ stranded & & & & & & \\
\hline
\end{tabular}

${ }^{a}$ Corrected for loss by using virion RNA as the control. Structure of VPg $\cdot \mathrm{pUp}$ is assumed (12).

RNase, which yielded VPg, free U (85\%), C, and G. Some radioactivity containing exclusively $A$ residues was left at the origin. We take these results to indicate that the $\mathrm{A}$ residues are resid-

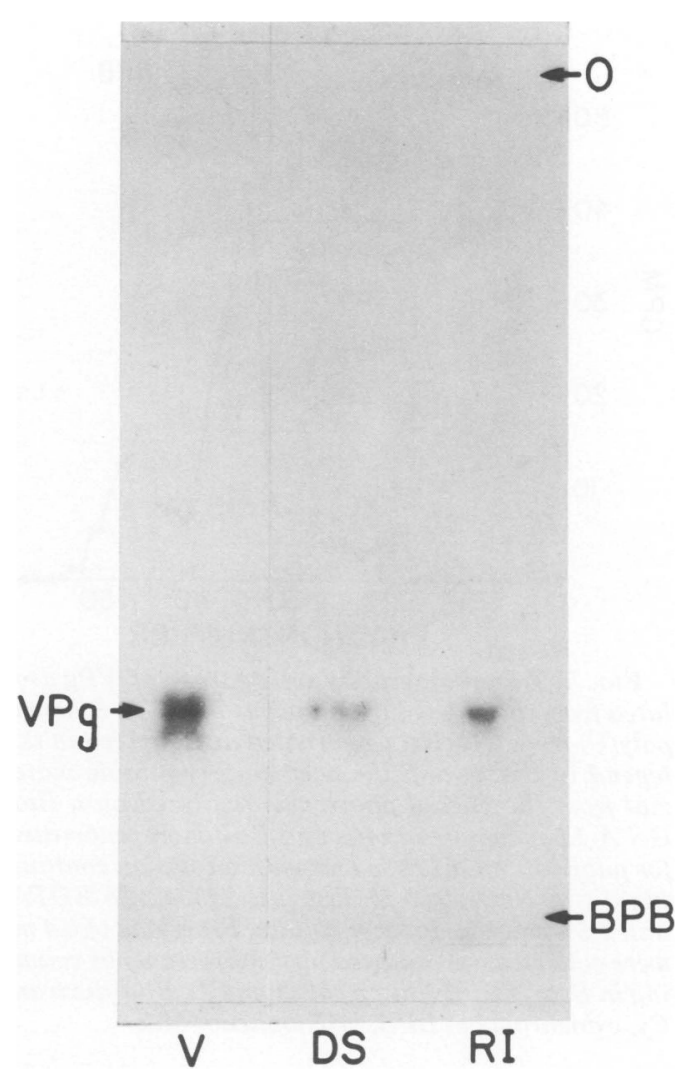

FIG. 6. Sodium dodecyl sulfate-polyacrylamide gel analysis of $\mathrm{VPg}$ from purified poly $(U)$ derived from poliovirus RI and double-stranded RNAs. Purified $\operatorname{poly}(U)$ isolated from $R I$ and double-stranded RNAs was digested with RNase $T 1, T 2$, and $A$, and the digests were phenol extracted. The protein was pre cipitated from the phenol phase by acetone and analyzed by electrophoresis through a 10 to $20 \%$ gradient polyacrylamide slab gel. VPg from labeled poliovirion RNA was prepared similarly and used as a control (left lane, V). RI, VPg from RI RNA; DS, VPg from double-stranded RNA; BPB, bromophenol blue; $\mathrm{O}$, origin.

ual contaminants and not covalently linked to the poly(U) tract.

\section{DISCUSSION}

We have demonstrated that a protein of the same size and electrophoretic mobility as the one on poliovirion RNA is covalently linked to the $5^{\prime}$ end of nascent strands of the RI and double-stranded RNAs. No other species of ${ }^{32} \mathrm{P}$. labeled protein could be extracted from any virus-specific RNAs. It is therefore likely that the same species of protein is linked to virion RNA, nascent plus strands, and minus strands.

Nascent plus strands. VPg was found to be linked to nascent plus strands of all lengths. 


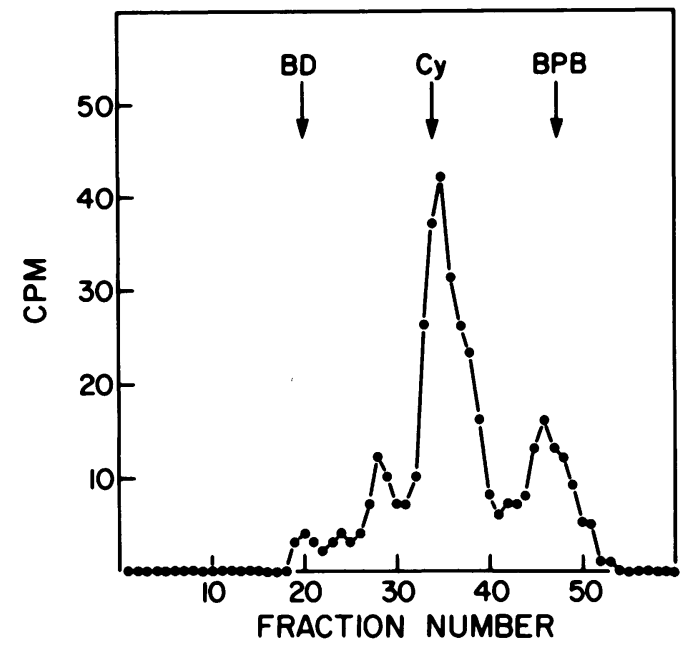

Fig. 7. Chromatography on agarose of VPg isolated from the poly $(U)$ of poliovirus RI RNA. Purified $\operatorname{poly}(U)$ from RI RNA was treated as described in the legend to Fig. 6, and the acetone-precipitable material from the phenol phase was analyzed on a BioGel A-1.5 column (Ambros and Baltimore, submitted for publication). Elution was with a solution containing $0.1 \mathrm{M} \mathrm{NaCl}, 0.05 \mathrm{M}$ Tris (pH 7.5), $1 \mathrm{mM} \mathrm{EDTA}$, and $0.5 \%$ sodium dodecyl sulfate. Fractions of $0.4 \mathrm{ml}$ were collected and assayed for radioactivity by counting in Bray's scintillation solution. BD, Blue dextran; $C y$, cytochrome c; BPB, bromophenol blue.

Fingerprint analysis of the nascent chains showed that agarose exclusion chromatography gave a true size fractionation because the relative yield of some $\mathrm{T} 1$ oligonucleotides was lower in smaller-sized RNA. These oligonucleotides were presumably derived from the $3^{\prime}$ portion of the genome. Those oligonucleotides whose relative intensity remained high in the fractions containing short RNA chains (e.g., 4, 11A, 27B [Fig. 2]) would then be derived from the $5^{\prime}$ portion of the genome. This analysis is supported by the finding that oligonucleotide 27B is lacking from poliovirus defective interfering particle RNA (11), and the deletion in this RNA is known to be close to the $5^{\prime}$ end (5).

The ratio of the relative molar yield of VPg to that of nascent chains was close to $1: 1$ for chain lengths between 7,500 and 2,500 nucleotides. Thereafter (pools 8 to 15 [Fig. 1B and Table 1]), the ratio varied between $0.3: 1$ and $0.6: 1$. Accurate estimation of the ratio of VPg to chains shorter than about 2,500 nucleotides was difficult, however, because: (i) no size marker shorter than $0.5 \times 10^{6}$ daltons was used to show that a linear relationship between the logarithm of the molecular weights and elution position actually existed for the short RNA; (ii) the size fractionation of short chains may not have been as good as for larger RNA molecules, especially because trailing of larger molecules into fractions with shorter molecules occurred; and (iii) some degradation of RNA may have occurred, resulting in short molecules lacking a protein at their $5^{\prime}$ end. The last two possibilities are supported by the fingerprint analysis of RNA from pools 11 and 14, showing that neither the oligonucleotides presumably mapping close to the $3^{\prime}$ end nor the poly(A) tract, the sequence closest to the $3^{\prime}$ end, disappeared completely. That the apparent discrepancy between the yield of VPg relative to the short RNA molecules is an artifact rather than real is further supported by the fact that no other 5 -terminal structure could be detected in any size class of RNA. Our data are therefore consistent with the idea that all nascent plus strands have a molecule of VPg covalently attached at their $5^{\prime}$ end.

Poliovirus mRNA isolated from polyribosomes lacks VPg, but its 5'-nucleotide sequence is identical to that of virion RNA (13). The recovery of VPg from nascent RNA molecules implies, as suggested previously (13), that VPg must be cleaved from a fraction of newly made RNA strands to give rise to the $5^{\prime}$-pUp found on polyribosomal RNA. Because no pUp could be demonstrated on the nascent chains, cleavage apparently does not take place while the RNA is still associated with the RI RNA.

Minus strands. The yield of radioactivity attached to VPg from the poly(U) tract of the negative strands of either RI or double-stranded RNAs was 1.3 to $1.5 \%$ of the total radioactivity in the $\operatorname{poly}(\mathrm{U})$ tract. We did not further characterize the structure of the nucleotide(s) attached to the protein. Nomoto et al. (12) have recently reported the isolation of a protein from the poly(U) of poliovirus RI RNA and doublestranded RNA after a treatment with RNases T1, T2, and A similar to the one that we have used here and showed that pUp could be released from the protein after digestion with venom phosphodiesterase. This indicates that the linkage between the protein and the poly $(\mathrm{U})$ may be the same as that to the virion RNA. If the protein is covalently linked to $\mathrm{pUp}$, the yield of protein-pUp would give an average length of about 120 to 140 nucleotides for the poly(U). This is in good agreement with our previous size estimates from polyacrylamide gels (17). Nomoto et al. (12) reported a yield of protein-pUp about 2.5 times higher than ours, giving an average length of only 30 to 50 nucleotides for the poly(U). VPg was covalently linked to the poly(U) sequences, because it could only be removed enzymatically. The $\mathrm{Gp}$ residue recovered from the RNase T1-resistant poly(U) must be located at the $3^{\prime}$ end. Therefore, VPg must be 
linked to the $5^{\prime}$ end because no other $5^{\prime}$ end structure was recovered in molar yield. We could, however, consistently detect trace amounts (maximum $0.2 \%$ ) of radioactivity in material migrating as pUp. Whether this actually was derived from the $5^{\prime}$ end of intact poly $(U)$ molecules or from the $5^{\prime}$ end of degraded molecules is not known. If it is derived from true $5^{\prime}$ termini, it could mean that $\mathrm{VPg}$ may be cleaved from some minus strands, possibly by the same mechanism as it is cleaved from newly made plus strands.

Function of VPg. The presence of VPg on the nascent chains of the RI RNA and the absence of pUp on any other $5^{\prime}$ end structure are consistent with the hypothesis that $\mathrm{VPg}$ is linked to the RNA at an early stage of RNA synthesis, possibly as a primer $(7,13)$. The finding of VPg on the negative-strand RNA as well suggests that the mechanism by which this RNA is synthesized may be similar to that of plus-strand RNA.

\section{ACKNOWLEDGMENTS}

This work was supported by Public Health Service grant AI-08388 from the National Institute of Allergy and Infectious Diseases and grants CA-14051 and CA-12174 from the National Cancer Institute. R.F.P. was a recipient of Public Health Service international fellowship F05 TW-2245 from the Fogarty International Center. D.B. is an American Cancer Society Research Professor.

\section{LITERATURE CITED}

1. Baltimore, D. 1968. Structure of the poliovirus replicative intermediate RNA. J. Mol. Biol. 32:359-368.

2. Baltimore, D., and M. Girard. 1966. An intermediate in the synthesis of poliovirus RNA. Proc. Natl. Acad. Sci. U.S.A. 56:741-748.

3. Baltimore, D., M. Girard, and J. Darnell. 1966. Aspects of the synthesis of poliovirus RNA and the formation of virus particles. Virology 29:179-189.

4. Barrell, B. G. 1971. Fractionation and sequence analysis of radioactive nucleotides. p. 751-828. In G. L. Cantoni and D. R. Davies (ed.), Procedures in nucleic acid research, vol. 2. Harper \& Row, New York.

5. Cole, C. N., and D. Baltimore. 1973. Defective interfer- ing particles of poliovirus. II. Nature of the defect. J. Mol. Biol. 76:325-344.

6. DeWachter, R., and W. Fiers. 1972. Preparative twodimensional polyacrylamide gel electrophoresis of ${ }^{32} \mathrm{P}$ RNA. Anal. Biochem. 49:184-197.

7. Flanegan, J. B., R. F. Pettersson, V. Ambros, M. J. Hewlett, and D. Baltimore. 1977. Covalent linkage of a protein to a defined nucleotide sequence at the $5^{\prime}$ terminus of the virion and replicative intermediate RNAs of poliovirus. Proc. Natl. Acad. Sci. U.S.A. 74:961-965.

8. Hewlett, M. J., J. K. Rose, and D. Baltimore. 1976. 5' Terminal structure of poliovirus polyribosomal RNA is pUp. Proc. Natl. Acad. Sci. U.S.A. 73:327-330.

9. Laemmli, U. K. 1970. Cleavage of structural proteins during the assembly of the head of bacteriophage T4. Nature (London) 227:680-685.

10. Lee, Y. F., A. Nomoto, B. M. Detjen, and E. Wimmer. 1977. A protein covalently linked to poliovirus genome RNA. Proc. Natl. Acad. Sci. U.S.A. 74:59-63.

11. Lee, Y. F., and E. Wimmer. 1976. Fingerprinting high molecular weight RNA by two-dimensional gel electrophoresis: application to poliovirus RNA. Nucleic Acids Res. 3:1647-1657.

12. Nomoto, A., B. Detjen, R. Pozzatti, and E. Wimmer. 1977. The location of the polio genome protein in viral RNAs and its implication for RNA synthesis. Nature (London) 268:208-213.

13. Pettersson, R. F., J. B. Flanegan, J. K. Rose, and D. Baltimore. 1977. 5' Terminal nucleotide sequence of poliovirus polyribosomal RNA and virion RNA are identical. Nature (London) 268:270-272.

14. Pettersson, R. F., M. J. Hewlett, and D. Baltimore. 1977. The genome of Uukuniemi virus consists of three unique RNA segments. Cell 11:51-63.

15. Sanger, D. U., D. J. Rowlands, T. J. R. Harris, and F. Brown. 1977. Protein covalently linked to foot and mouth disease virus RNA. Nature (London) 268:648-650.

16. Spector, D. H., and D. Baltimore. 1975. Polyadenylic acid on poliovirus RNA. II. Poly(A) on intracellular RNAs. J. Virol. 15:1418-1431.

17. Spector, D. H., and D. Baltimore. 1975. Polyadenylic acid on poliovirus RNA. IV. Poly(U) in replicative intermediate and double-stranded RNA. Virology 67:498-512.

18. Yogo, Y., M. Teng, and E. Wimmer. 1974. Poly(U) in poliovirus minus RNA is $5^{\prime}$ terminal. Biochem. Biophys. Res. Commun. 61:1101-1109.

19. Yogo, Y., and E. Wimmer. 1973. Poly(A) and poly(U) in poliovirus double stranded RNA. Nature (London) New Biol. 242:171-174. 